\title{
Dementia in Aboriginal and Torres Strait Islander people
}

\author{
An urgent imperative to close the gap
}

T he article by Li and colleagues ${ }^{1}$ in this issue of the Journal highlights an important emerging public health problem for Australia's Aboriginal and Torres Strait Islander population that incorporates many health issues relevant to the "close the gap" initiative.

The results of the prevalence study of dementia in the Indigenous population of the Northern Territory over 45 years of age show that they experience dementia at a much higher rate compared with other Australians. This is consistent with another recent review from the Kimberley, Western Australia, that showed that the prevalence of dementia in the Indigenous population in that area was five times greater than in the non-Indigenous population, and that dementia occurred at an earlier age. ${ }^{2}$ The ongoing Koori Growing Old Well Study of Indigenous communities in New South Wales, led by Tony Broe of Neuroscience Research Australia, has also found a prevalence rate of dementia in older people resident in these communities of about three times the prevalence in nonIndigenous Australians. ${ }^{3,4}$ A particular concern related to the NT study is the finding of higher incidence rate ratios of dementia for the younger Aboriginal male and female Territorians in the 45-64-years age group. ${ }^{1}$

There are a number of factors across the life span of Aboriginal and Torres Strait Islander people that are likely to affect this disturbing trend. One such factor may be high rates of intellectual disability in children (at double the rate of other residents) recently identified in the Kimberley region. ${ }^{5}$ Early health risk factors such as higher rates of obstetric complications in young mothers, ${ }^{6}$ low-birthweight babies, ${ }^{6}$ child hood malnutrition and retarded growth ${ }^{7}$ along with reduced participation in education ${ }^{8}$ may be predisposing factors to this unfortunate phenomenon in addition to being risk factors for later dementia.

Other abnormal health risk factors in Aboriginal and Torres Strait Islander people, such as double the rate of traumatic injury, higher rates of smoking and markedly increased rates of chronic illness such as diabetes and cardiovascular and renal disease, ${ }^{6}$ are further likely contributing factors.

With higher rates of problematic alcohol misuse generally being reported in Indigenous Australians, ${ }^{9}$ the role of such alcohol misuse in the increasing prevalence of dementia is of particular concern. The contribution of fetal alcohol syndrome as a cause of intellectual disability (with its potential contribution to the above noted increased rates of intellectual disability in younger Indigenous Australians) is also being increasingly recognised in WA and the NT. ${ }^{10}$ Alcohol as a specific contributor to dementia was noted in $7.4 \%$ of Indigenous Australians in the NT study ${ }^{1}$ and problematic alcohol misuse was also noted in just under half the people affected by dementia in the Kimberley study. ${ }^{2}$

The actual diagnostic categories of dementia, in the context of the reluctance of many Indigenous Australians to have routine autopsy performed on family, ${ }_{1}^{11}$ in addition to cultural and language factors that may affect a specific diagnosis, may be difficult to validate in Indigenous Australians. This is typified by the NT study that noted that "documented" Alzheimer disease and vascular dementia made up only about $35 \%$ of the total Indigenous dementia group, ${ }^{1}$ when the actual rate is likely to be higher.

A contribution that may assist with more accurate diagnosis is the development of appropriate, culturally relevant screening tools for defining cognitive impairment in the Aboriginal and Torres Strait Islander population. The Kimberley Indigenous Cognitive Assessment is an example of such a tool. ${ }^{12}$

Many of the contributing health risk factors are still active and a target of the "close the gap" health initiative for Indigenous Australians. It is therefore imperative that a broad-based view of health across the life span is taken into account to tackle a serious emerging epidemic of brain disease. This epidemic has important funding, ethical, legal ${ }^{13}$ and health service delivery implications that are distinct among the general health concerns in respect to an ageing Australian population.

Competing interests: No relevant disclosures.

Provenance: Not commissioned; externally peer reviewed.

1 LiSQ, Guthridge SL, Aratchige PE, et al. Dementia prevalence and incidence among the Indigenous and non-Indigenous populations of the Northern Territory. Med J Aust 2014; 200: 465-469.

2 Smith K, Flicker L, Lautenschlager NT, et al. High prevalence of dementia and cognitive impairment in Indigenous Australians. Neurology 2008; 71: $1470-1473$.

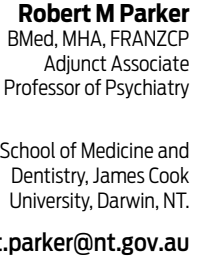

doi: 10.5694/mjal4.00259 
3 Neuroscience Research Australia. Koori Growing Old Well Study. http:// www.neura.edu.au/aboriginal-ageing (accessed Apr 2014).

4 Dementia soars in Aboriginal communities. DPS News [internet] 2013; 23 May. http://www.agedcareguide.com.au/news/2013/05/23/dementiasoars-in-aboriginal-communities (accessed Apr 2014).

5 Glasson EJ, Sullivan SG, Hussain R, Bittles AH. An assessment of intellectual disability among Aboriginal Australians. J Intellect Disabil Res 2005; 49: 626-634.

6 Australian Institute of Health and Welfare. The health and welfare of Australia's Aboriginal and Torres Strait Islander people: an overview. Canberra: AlHW, 2011. (AlHW Cat. No. IHW 42.) http://www.aihw.gov.au/ publication-detail/?id=10737418989 (accessed Apr 2014).

7 Skull SA, Ruben AR, Walker AC. Malnutrition and microcephaly in Australian Aboriginal children. Med J Aust 1997; 166: 412-414.

8 Zubrick SR, Silburn SR, De Maio JA, et al. Educating Aboriginal children issues, policy and history. In: The Western Australian Aboriginal Child Health Survey: improving the educational experiences of Aboriginal children and young people. Vol. 3. Perth: Curtin University of Technology and Telethon Institute for Child Health Research, 2006: Ch. 2. http://aboriginal. telethonkids.org.au/media/395500/western_australian_aboriginal_child_ health_survey_ch2.pdf (accessed Apr 2014).
9 Wilkes E, Gray D, Saggers S, et al. Substance misuse and mental health among Aboriginal Australians. In: Purdie N, Dudgeon P, Walker R, editors. Working together: Aboriginal and Torres Strait Islander mental health and wellbeing principles and practice. Canberra: Commonwealth of Australia, 2010:117-134. http://aboriginal.childhealthresearch.org.au/media/54847/ working_together_full_book.pdf (accessed Apr 2014).

10 Harris KR, Bucens IK. Prevalence of fetal alcohol syndrome in the Top End of the Northern Territory. J Paediatr Child Health 2003; 39: 528-533.

11 Carpenter B, Tait G, Quadrelli C. Arguing the autopsy: mutual suspicion, jurisdictional confusion and the socially marginal. In: Richards K, Tauri $\mathrm{J}$, editors. Crime, justice and social democracy: proceedings of the 2 nd International Conference. Vol. 1. Brisbane: Crime and Justice Research Centre. Queensland University of Technology, 2013: 10-18. http://crimejusticeconference.com/wp-content/uploads/2012/12/ Conference-Proceedings-Vol-1_2013.pdf (accessed Apr 2014).

12 LoGiudice D, Smith K, Thomas J, et al. Kimberley Indigenous Cognitive Assessment tool (KICA): development of a cognitive assessment tool for older indigenous Australians. Int Psychogeriatr 2006; 18: 269-280.

13 Sotiri M, McGee P, Baldry E. No end in sight. The imprisonment and indefinite detention of Indigenous people with a cognitive impairment. Sydney: University of New South Wales, 2012. http://www.pwd.org.au/documents/ project/2012ADJC-NoEndlnSight.docx (accessed Apr 2014). 